\title{
Supramolecular micellar nanoaggregates based on a novel chitosan/vitamin E succinate copolymer for paclitaxel selective delivery
}

This article was published in the following Dove Press journal:

International Journal of Nanomedicine

9 December 2011

Number of times this article has been viewed

\section{He Lian' \\ Jin Sun' \\ Yan Ping Yu' \\ Yan Hua Liu \\ Wen $\mathrm{Cao}^{\prime}$ \\ Yong Jun Wang' \\ Ying Hua Sun' \\ Si Ling Wang' \\ Zhong Gui He'}

'School of Pharmacy, Shenyang Pharmaceutical University, Shenyang, ${ }^{2}$ Department of Pharmaceutics, School of Pharmacy, Ningxia Medical University, Ningxia, People's Republic of China
Correspondence: Zhong Gui He Department of Pharmaceutics, Shenyang Pharmaceutical University, 103 Wenhua Road, Shenyang I I00 I6, People's Republic of China

Tel/Fax +86 242398632

Email hezhonggui@gmail.com

Jin Sun

Department of Biopharmaceutics, Shenyang Pharmaceutical University, 103 Wenhua Road, Shenyang I I0016, People's Republic of China

Tel +862423986325

Fax +862423986320

Email sunjin66@2Icn.com
Background: Nowadays, many cytotoxic anticancer drugs exhibit low solubility and poor tumor selectivity, which means that the drug formulation is very important. For example, in the case of paclitaxel (PTX), Cremophor EL ${ }^{\circledR}$ (BASF, Ludwigshafen, Germany) needs to be used as a solubilizer in its clinical formulation (Taxol ${ }^{\circledR}$, Bristol-Myers Squibb, New York, NY), although it can cause serious side effects. Nanomicellar systems are promising carriers to resolve the above problems, and the polymer chosen is the key element.

Methods: In this study, a novel amphiphilic chitosan/vitamin E succinate (CS-VES) copolymer was successfully synthesized for self-assembling polymeric micelles. Proton nuclear magnetic resonance spectroscopy and infrared were used to characterize the molecular structure of the copolymer. The PTX-loaded CS-VES polymeric micelles (PTX-micelles) were characterized by dynamic light scattering, transmission electron microscopy, X-ray diffraction, and differential scanning calorimetry.

Results: The critical micelle concentration of CS-VES was about $12.6 \mu \mathrm{g} / \mathrm{mL}$, with the degree of amino group substitution being $20.4 \%$. PTX-micelles were prepared by a nanoprecipitation/ dispersion technique without any surfactant being involved. PTX-micelles exhibited a drug loading as high as $21.37 \%$ and an encapsulation efficiency of $81.12 \%$, with a particle size ranging from 326.3 to $380.8 \mathrm{~nm}$ and a zeta potential of $+20 \mathrm{mV}$. In vitro release study showed a near zero-order sustained release, with $51.06 \%, 50.88 \%$, and $44.35 \%$ of the PTX in the micelles being released up to 168 hours at three drug loadings of $7.52 \%, 14.09 \%$, and $21.37 \%$, respectively. The cellular uptake experiments, conducted by confocal laser scanning microscopy, showed an enhanced cellular uptake efficiency of the CS-VES micelles in MCF-7 cells compared with Taxol. The PTX-micelles exhibited a comparable but delayed cytotoxic effect compared with Taxol against MCF-7 cells, due to the sustained-release characteristics of the nanomicelles. More interestingly, blank nanomicelles based on CS-VES copolymer demonstrated significant cytotoxicity against MCF-7 cells.

Conclusion: The supramolecular micellar aggregates based on CS-VES copolymer is a promising nanocarrier and efficacy enhancer when used as an anticancer drug-delivery system.

Keywords: nanomicelles, cellular uptake, cytotoxicity

\section{Introduction}

Paclitaxel (PTX), a natural hydrophobic diterpenoid extracted from the bark of the Pacific yew, is a microtubule stabilizer used in cancer chemotherapy. PTX is widely used for the treatment of various solid tumors, including non-small cell lung, ovarian, breast, and prostate cancers. ${ }^{1-3}$ However, its clinical application has been severely limited by its poor aqueous solubility, about $1 \mu \mathrm{g} / \mathrm{mL}$ in water. So, the commercial PTX formulation (Taxol ${ }^{\circledR}$, Bristol-Myers Squibb, New York, NY) was prepared with 
the aid of Cremophor EL ${ }^{\circledR}$ (BASF, Ludwigshafen, Germany) and absolute alcohol (50:50, v/v). However, severe toxic side effects can be caused by the use of Cremophor EL, such as hypersensitivity, neurotoxicity, and nephrotoxicity, and thus, patients require appropriate premedication.

In recent years, significant progress has been made in the development of novel PTX delivery systems, such as liposomes, ${ }^{4}$ emulsions, ${ }^{5,6}$ hydrogels, ${ }^{7}$ and polymeric micelles. ${ }^{8-12}$ Notable among these delivery systems are polymeric micelles because of their outstanding advantages, including the self-assembly of core-shell micelles in an aqueous environment, a smaller size and uniform size distribution, prolonged circulation time in the bloodstream, passive accumulation in solid tumors achieved by permeability and a retention effect, and easy surface functionalization with many targeting receptors (eg, folic acid, transferrin, and trastuzumab) for improved intracellular tumor exposure. ${ }^{13-17}$

A range of natural or synthetic polymers have been used to develop polymeric micellar delivery nanosystems. Chitosan, a polysaccharide derived from chitin by incomplete or complete deacetylation, is a promising choice. ${ }^{18,19}$ Most importantly, it is an alkalescent polysaccharide found in nature, and so it is readily available, with good biodegradability and biocompatibility, and no apparent toxicity during long-term therapy. Secondly, nanomicelles formed by chitosan derivatives generally carry a positive charge on their surface, which contributes to the bioadhesive ability of the formulation and gene delivery by forming complexes with negatively charged deoxyribonucleic acid (DNA).${ }^{20}$ Thirdly, it possesses good amenability to functional surface modification (eg, folic acid ${ }^{21}$ and polyethylene glycol ${ }^{22}$ ) due to the high number of available hydroxyl and amino groups on the surface. In the past decade, polymeric micelles based on chitosan have been developed rapidly, and much progress has been made. For example, the amphiphilic N-octyl-O-sulfate chitosan was synthesized, and improves the solubility of PTX up to $2.6 \mathrm{mg} / \mathrm{mL}, 1000$ times higher than in water. ${ }^{23}$ In addition, the antitumor efficiency of N-octyl-O-sulfate chitosan is similar to Taxol but produces less toxicity. ${ }^{24}$ Another study reports that stearic acid (SA) can be grafted with chitosan oligosaccharide (CSO). ${ }^{25}$ This new CSO/SA copolymer can significantly condense the plasmid DNA and exhibits a marked transfection enhancement compared with CSO. Hydrophobically modified glycol chitosan nanoparticles with cholanic acid as the hydrophobic core have been prepared to encapsulate the anticancer drug docetaxel (DTX). ${ }^{26}$ DTX nanoparticles are stable and well dispersed under physiological conditions, and they exhibit a better tumor-targeting ability compared with DTX solution and increase the survival rate in A-549 lung cancer cell-bearing mice.

In recent years, vitamin $\mathrm{E}$ succinate $(R R R$ - $\alpha$-tocopheryl succinate, VES), an esterified redox-silent analog of vitamin $\mathrm{E}$, has had more attention than other compounds in the vitamin $\mathrm{E}$ family. It can induce apoptosis of malignant cells without any toxicity to normal cells. ${ }^{27,28}$ Great efforts have been made to explain the selective apoptosis mechanism of VES, and it has been found that VES can trigger rapid production of reactive oxygen species, ${ }^{29}$ and induce caspase-dependent apoptosis by inhibiting the combination of Bcl-2 and Bcl-xl with Bcl-2 homology 3 (BH3). ${ }^{30}$ In combination, VES is a potent inducer of apoptosis in cancer cells, rather than in normal cells, and thus, is a promising efficacy enhancer in cancer chemotherapy.

With regards to the hydrophobicity and enhanced anticancer efficacy of VES, the authors of this paper designed a new chitosan-VES (CS-VES) copolymer for the first time, in which VES was the hydrophobic portion and chitosan was the hydrophilic backbone (Figure 1A). The amphiphilic CS-VES copolymer self-assembled nanomicelles in aqueous conditions and efficiently encapsulated

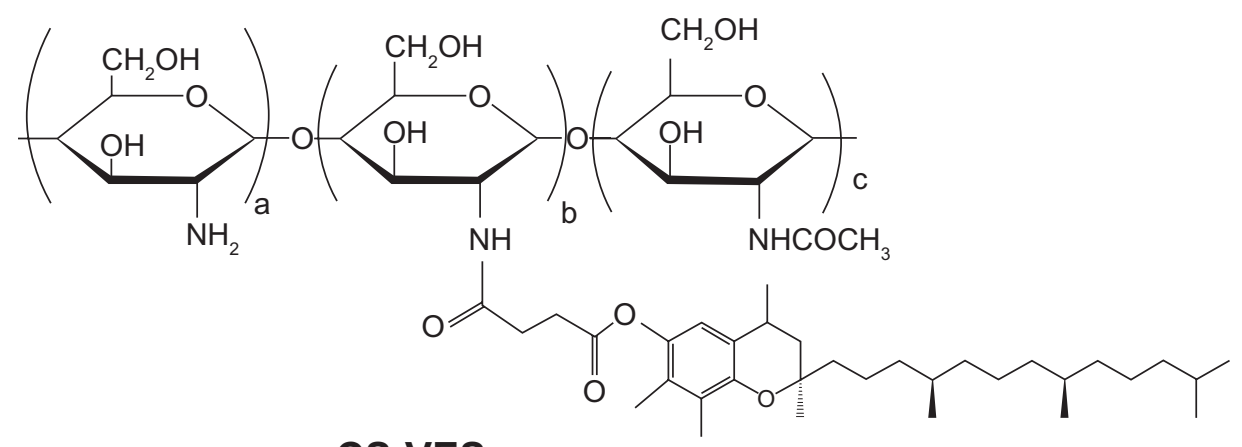

\section{CS-VES}

Figure IA Chemical structure of chitosan/vitamin E succinate (CS-VES). 


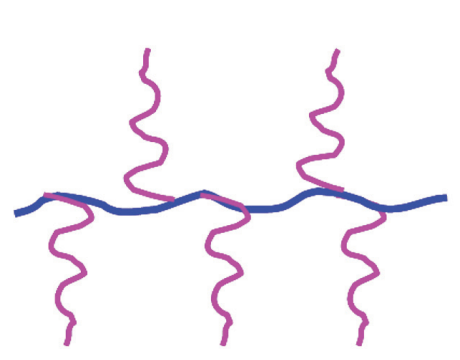

CS-VES copolymer

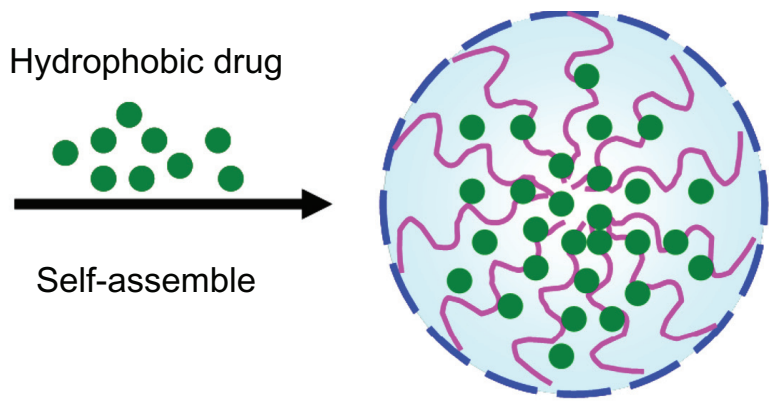

CS-VES micelle

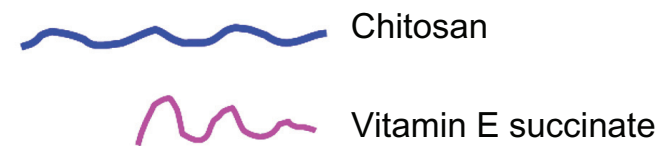

Figure IB Illustration of the self-assembled micelles formed by CS-VES copolymer under aqueous conditions. Abbreviation: CS-VES, chitosan/vitamin E succinate.

the hydrophobic anticancer drug, PTX, used in this study (Figure 1B). Firstly, and most importantly, blank nanomicelles formed by CS-VES copolymer exhibited significant cytotoxicity against MCF-7 cells but had no apparent effect on hemolysis and erythrocyte agglutination at the highest concentration of $2 \mathrm{mg} / \mathrm{mL}$. These results suggest that supramolecular micellar nanoaggregates based on the novel CS-VES copolymer are a promising nanocarrier for anticancer drug delivery.

\section{Materials and methods Materials}

Chitosan (molecular weight $=20 \mathrm{KDa}$; degree of deacetylation $=92.5 \%$ ) was purchased from Aoxing Biochemical Co, Ltd (Zhejiang, China). VES was purchased from Yuancheng Technology Development Co, Ltd (Wuhan, China). PTX was obtained from Xi' an Helin Biological Engineering Co, Ltd (Xi'an, China). EDC (1-ethyl-3-(3-dimethylaminopropyl)carbodiimide hydrochloride) was obtained from Shanghai Medpep Co, Ltd (Shanghai, China). Coumarin-6, -2, and -4, 6-trinitrobenzenesulfonic acid solution (TNBS), and pyrene were purchased from Sigma (St Louis, MO). All other chemicals and reagents were of analytical grade, and used without further purification.

\section{Synthesis of CS-VES copolymer}

CS-VES copolymer was prepared by conjugating the carboxyl group of VES with the amino groups of chitosan in the presence of EDC. The chemical structure of CS-VES is shown in Figure 1. In brief, chitosan (200 mg) was dissolved in $20 \mathrm{~mL}$ of $1.25 \%$ acetic acid solution, and VES (600 mg) was dissolved in $25 \mathrm{~mL}$ absolute ethyl alcohol followed by the addition of a suitable amount of EDC. These were then mixed in a flask and heated to $70^{\circ} \mathrm{C}$ for 5 hours under mechanical stirring. The mixture was allowed to cool to room temperature for another 24 hours to allow further reaction, and the product was dialyzed in ethyl alcohol using a dialysis membrane (molecular weight cutoff $[\mathrm{MWCO}]=12 \mathrm{KDa}$; Spectrum Laboratories, Ft Lauderdale, FL) to remove hydrophobic remains, then dialyzed in distilled water to remove hydrophilic byproducts, followed by freeze drying.

The chemical structure of the conjugate was analyzed using proton nuclear magnetic resonance spectroscopy $\left({ }^{1} \mathrm{H}-\right.$ $\mathrm{NMR})$ in $\mathrm{D}_{2} \mathrm{O} / \mathrm{DCl}(5: 1, \mathrm{v} / \mathrm{v})$ solution at $300 \mathrm{MHz}$, and the infrared (IR) spectrum was recorded (Figure 2). The degree of substitution of the amino groups of chitosan was determined by the TNBS method. ${ }^{31}$

\section{Preparation of PTX- or coumarin-6- loaded micelles}

PTX-loaded micelles were prepared by the nanoprecipitation/ dispersion technique involving the probe-type ultrasonic method. Briefly, $15 \mathrm{mg}$ CS-VES conjugate was dissolved in $6 \mathrm{~mL}$ diluted acetic acid, PTX was dissolved in absolute ethyl alcohol, and then the drug solution was added dropwise to the CS-VES solution. The mixture was then stirred at room temperature for 12 hours to vaporize the nonaqueous solvent. The resulting solution was then sonicated four times using a probe-type sonifier (JY92-2D, Scientz, Ningbo, China) at $200 \mathrm{~W}$ for 5 minutes with the pulse turned off for 2 seconds at intervals of 3 seconds. The sonication process was carried out in an ice-bath to keep the temperature low. After that, the micelle solution was centrifuged at $3500 \mathrm{rpm}$ for 20 minutes 
to remove any unloaded drug. The micelles loaded with fluorescent coumarin- 6 were prepared in the same way, except that coumarin- 6 was added to the micelle solution instead of PTX. The supernatant micelles were filtered through a $0.8 \mu \mathrm{m}$ syringe filter to remove any impurities before being stored at $4^{\circ} \mathrm{C}$.

\section{Characterization of PTX-loaded micelles} Size and zeta potential

The size and size distribution of the micelles were measured by dynamic light scattering (Nicomp TM 380, Particle Sizing Systems Inc, Santa Barbara, CA). The zeta potential of the micelles was determined using a ZetaPlus zeta potential analyzer (Delsa440SX, Beckmann-Coulter Electronics, Krefeld, Germany). The micelles were diluted with deionized water before measurement.

\section{Drug encapsulation efficiency}

The PTX content entrapped in the micelles was measured by high performance liquid chromatography (HPLC) (Shimadzu, Kyoto, Japan). A reverse-phase ODS Diamonsil ${ }^{\text {TM }}$ C18 (Dikma, Beijing, China) column (250 mm ×4.6 mm, $5 \mu \mathrm{m}$ ) was used. In brief, $1 \mathrm{~mL}$ of micellar solution was diluted with $25 \mathrm{~mL}$ of methyl alcohol and sonication was used to collapse the micelles and dissolve the drug. The solution was then injected to HPLC after filtering it through a $0.45 \mu \mathrm{m}$ syringe filter. The flow rate of the mobile phase, consisting of acetonitrile and deionized water (60:40, v/v), was $1 \mathrm{~mL} / \mathrm{min}$. The column effluent was examined at $227 \mathrm{~nm}$ with a ultraviolet-visible detector. The calibration curve was linear over the range $2.5-50 \mu \mathrm{g} / \mathrm{mL}$, with a correlation coefficient of $\mathrm{R}^{2}=0.9999$. The encapsulation efficiency was calculated as the percentage ratio of the amount of PTX incorporated into micelles to the total feeding amount of PTX. The drug-loading percentage was defined as the ratio of the PTX content to the amount of drug-loaded micelles.

\section{Transmission electron microscopy (TEM)}

The morphology of the CS-VES micelles was examined by TEM (H-600, Hitachi, Tokyo, Japan). A drop of micelle solution was stained with $2 \%(\mathrm{w} / \mathrm{v})$ phosphotungstic acid for 3 minutes on a copper grid, followed by visualization under TEM.

\section{Critical micelle concentration (CMC)}

The CMC of the CS-VES micelles was estimated using a hydrophobic fluorescence probe, pyrene, as reported previously. ${ }^{32,33}$ For this, $100 \mu \mathrm{L}$ pyrene solution $\left(3 \times 10^{-5} \mathrm{~mol} / \mathrm{L}\right.$ in ethanol) was added to test tubes, and micelle solution ranging from 1 to $500 \mu \mathrm{g} / \mathrm{mL}$ was added to the tubes after evaporation of the ethanol. The solution was then equilibrated for 12 hours at room temperature in darkness, and sonicated for 30 minutes. At an excitation wavelength at $337 \mathrm{~nm}$ and emission wavelengths of 373 and $385 \mathrm{~nm}$, the emission spectra were recorded in a spectrofluorometer (F-2500, Hitachi).

\section{Physical status of PTX in the micelles}

The X-ray powder diffraction patterns were recorded in a Japan D/Max 2500 PC X-ray diffractomer (Rigaku, Tokyo, Japan) using graphite monochromatized $\mathrm{Cu} \mathrm{K} \alpha$ radiation in the range of $3^{\circ}-50^{\circ}(2 \theta)$ at $50 \mathrm{kV}$ and $300 \mathrm{~mA}$.

Differential scanning calorimetry (DSC) was carried out using a TA-60 WS instrument (Shimadzu) to examine the nature of PTX in the CS-VES micelles. Samples, including chitosan, PTX, blank excipient (CS-VES), lyophilized PTXmicelles, and a physical mixture of PTX and blank excipient were sealed with pinhole-pierced covers and analyzed at a heating rate of $10^{\circ} \mathrm{C} /$ minute from $25^{\circ} \mathrm{C}$ to $280^{\circ} \mathrm{C}$ under a stream of dry nitrogen.

\section{In vitro release study}

An in vitro drug release study was carried out by dialysis using phosphate-buffered saline (PBS) ( $\mathrm{pH} \mathrm{7.4,} \mathrm{containing}$ $2 \% \mathrm{w} / \mathrm{v}$ Cremophor $\mathrm{EL}^{\circledR}$ ) as the release medium. Cremophor EL was used as a solubilizer of the PTX in the buffer, and $1 \mathrm{~mL}$ Taxol solution or micelles with $0.25 \mathrm{mg}$ PTX were sealed in dialysis tubes $(\mathrm{MWCO}=14 \mathrm{KDa}$, Spectrum Laboratories) which were then immersed in $80 \mathrm{~mL}$ release medium. The tubes were placed in an incubator shaker at $100 \mathrm{rpm}$ and $37^{\circ} \mathrm{C}$. At selected intervals, $2 \mathrm{~mL}$ samples were withdrawn and replaced with the same volume of fresh medium. The amount of PTX released from the micelles was determined by HPLC, with the detector set at $227 \mathrm{~nm}$.

\section{Cell culture}

\section{Cellular uptake of fluorescent micelles}

MCF-7 (human breast carcinoma cell line) was provided by Kaiji Biotech Co, Ltd (Nanjing, China). The cells were incubated in RPMI (Roswell Park Memorial Institute)1640 medium containing $10 \%(\mathrm{v} / \mathrm{v})$ fetal bovine serum and $1 \%$ penicillin-streptomycin at $37^{\circ} \mathrm{C}$, under $5 \%$ humidity and $5 \% \mathrm{CO}_{2}$. They were then plated over a cover slide on a sixwell plate at a density of $2 \times 10^{5}$ cells per well for 24 hours at $37^{\circ} \mathrm{C}$. To describe the uptake of CS-VES micelles in MCF-7, coumarin-6 was encapsulated in the micelles as a probe to study the uptake, and images were recorded by confocal laser scanning microscopy. After the cells formed 


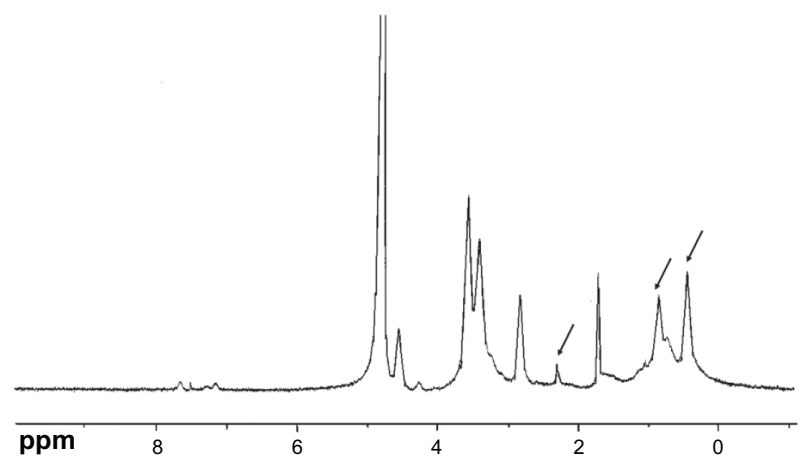

Figure 2A Proton nuclear magnetic resonance spectra of chitosan/vitamin E succinate conjugate (in $\mathrm{D}_{2} \mathrm{O} / \mathrm{DCl}, 5: \mathrm{l} / \mathrm{v}$ ).

a confluent monolayer, they were equilibrated with Hanks' balanced salt solution for 1 hour and then incubated with the coumarin-6-loaded micelles or coumarin-6 solution on the shaker. The cells were washed with cold PBS, fixed with $70 \%$ ethanol for 20 minutes, and then washed twice more with PBS. The nuclei were then stained with propidium iodine solution $(50 \mu \mathrm{g} / \mathrm{mL})$ for 30 minutes. The monolayer was then fixed on a glass slide with gum and examined under a laser confocal scanning microscope (TCS SP2/ AOBS, Leica, Heidelberg, Germany).

\section{In vitro cytotoxicity}

The cytotoxicity of CS-VES micelles (drug-loading ratio $21.37 \%$ ) was evaluated using MCF cells in comparison with a Taxol formulation. MCF-7 cells were seeded into a 96-well plate at a density of $2 \times 10^{3}$ cells per well and cultivated for 12 hours at $37^{\circ} \mathrm{C}$. The plate was then incubated with CS-VES micelles and Taxol at 1, 10, and $100 \mathrm{ng} / \mathrm{mL}$ and 1,10 , and $100 \mu \mathrm{g} / \mathrm{mL}$ equivalent PTX concentration and the same amount of blank excipient for 24, 48, and 72 hours, respectively. At selected intervals, $50 \mu \mathrm{L}$ microtiter tetrazolium (MTT) $(2 \mathrm{mg} / \mathrm{mL})$ was added to each well and incubated for a further 4 hours. After that, $200 \mu \mathrm{L}$ dimethylsulfoxide was added to each well to dissolve the MTT formazan. The absorbance at $570 \mathrm{~nm}$ was measured using a microplate reader (Model 500; BioRad, Hercules, CA). Each sample was analyzed in triplicate. The cell viability was defined by the following equation:

$$
\text { Cell viability }(\%)=\frac{\mathrm{OD}_{\mathrm{s}}}{\mathrm{OD}_{\text {control }}} \times 100 \% \text {, }
$$

where $\mathrm{OD}_{\mathrm{s}}$ was the optical density of the cells incubated with CS-VES micelles, and $\mathrm{OD}_{\text {control }}$ was the optical density of the cells treated only with culture medium. Half-maximal inhibitory concentration $\left(\mathrm{IC}_{50}\right)$, the drug concentration at which inhibition of $50 \%$ cell growth was obtained, was carried out by curve fitting of the cell viability data.

\section{Hemolysis test}

Dog blood was used to test the hemolysis effect of CS-VES copolymer. In brief, $10 \mathrm{~mL}$ whole blood was obtained from a

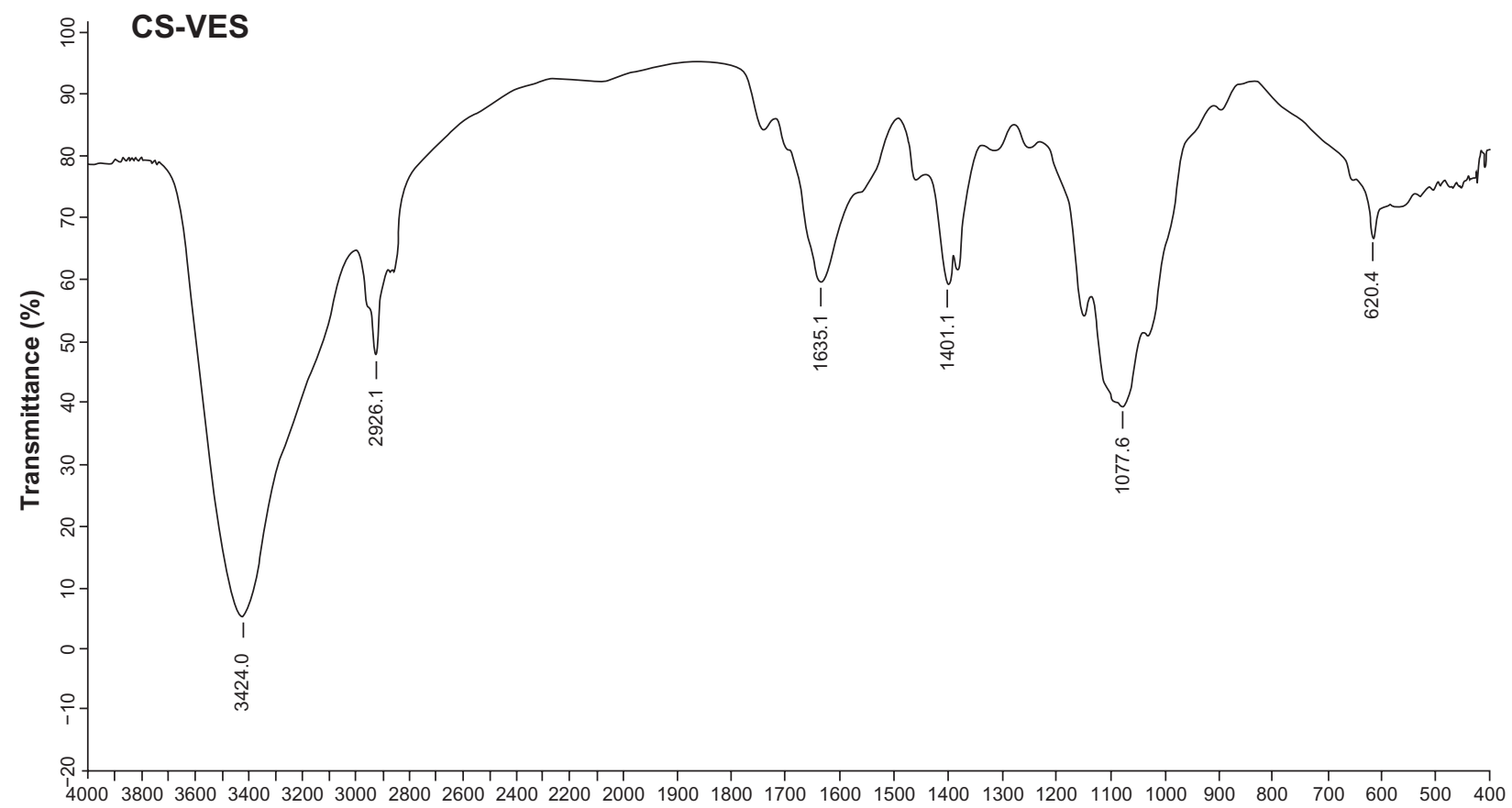

Wavenumber $\mathrm{cm}^{-1}$

Figure 2B Infrared spectrum of CS-VES.

Abbreviation: CS-VES, chitosan/vitamin E succinate. 
beagle dog. The fibrinogen was removed with tally after stirring. Then, $5 \mathrm{~mL}$ physiological saline was added to the fibrinogen-free blood sample, and the erythrocytes were collected after centrifugation at $2500 \mathrm{rpm}$ for 10 minutes. The pellets were then washed three times with physiological saline until the supernatant was not red. Finally, a suitable amount of physiological saline was added to the erythrocyte pellets to prepare a $2 \%$ erythrocyte standard dispersion. The CS-VES copolymer was dissolved in physiological saline at a concentration of $10 \mathrm{mg} / \mathrm{mL}$. Then, $0.125,0.25,0.5,0.75$, and $1 \mathrm{~mL}$ polymer solution, respectively, was added to the five tubes containing $2.5 \mathrm{~mL}$ erythrocyte pellets. Physiological saline was then added to every tube to give a final volume of $5 \mathrm{~mL}$. A negative control was prepared by mixing $2.5 \mathrm{~mL}$ physiological saline with $2.5 \mathrm{~mL} 2 \%$ erythrocyte dispersion, and the physiological saline was replaced by water to give a positive control. After blending, all the tubes were incubated at $37^{\circ} \mathrm{C}$ and observed every hour.

\section{Results and discussion Synthesis and characterization of the CS-VES copolymer}

CS-VES copolymer was successfully synthesized using EDC as a reaction catalyst by conjugating VES to the CS backbone. A strong proton peak of VES (at 0.4-1.0 ppm) appeared along with the proton peak of succinyl methylene (at about $2.5 \mathrm{ppm}$, Figure 2A). The IR spectrum further confirmed the formation of CS-VES conjugate (as shown in Figure 2B). The reduced intensity of the primary amines (at $3424 \mathrm{~cm}^{-1}$ ) confirmed that the amino groups of chitosan were substituted by VES. The enhanced peak (at $1635 \mathrm{~cm}^{-1}$ ) of the acetyl group and the appearance of the C-N linkage at $1404 \mathrm{~cm}^{-1}$ further confirmed the CS-VES structure. The degree of substitution of amino groups, estimated by the TNBS method was $20.4 \%$, indicating that the conjugate had been synthesized successfully.

Pyrene was used as a fluorescent probe to measure the $\mathrm{CMC}$ of the CS-VES copolymer. The CMC value was determined to be $12.6 \mu \mathrm{g} / \mathrm{mL}$ (Figure 3). The lower CMC

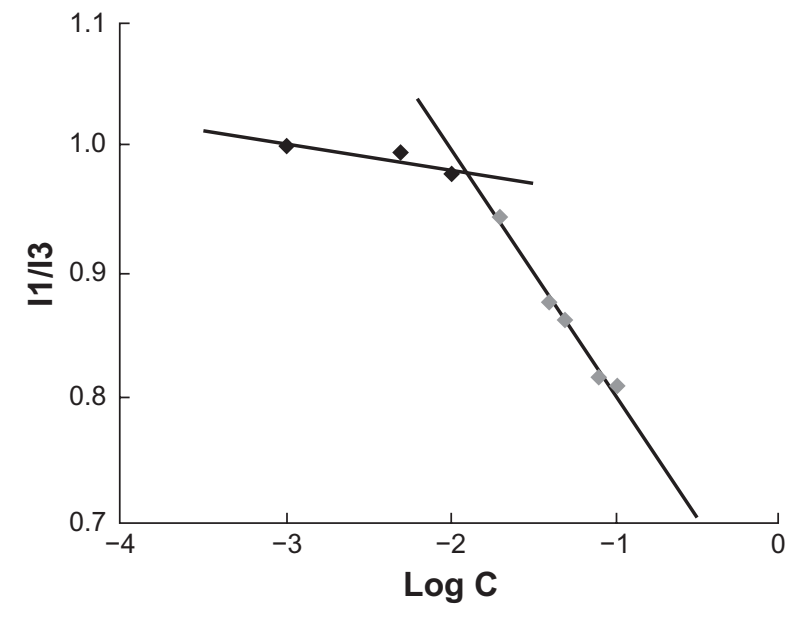

Figure 3 Variation of fluorescence intensity ratio (II/I3) versus logarithm of chitosan/vitamin E succinate concentration.

value indicated that the CS-VES copolymer can easily form a core-shell structure in an aqueous environment and retain the micellar structure integrity under diluted conditions in vitro and in vivo.

\section{Preparation and characterization of PTX-loaded micelles}

Size, zeta potential, drug loading, PTX content, and encapsulation efficiency

To prepare the anticancer PTX-loaded micelles, PTX solution was injected into the CS-VES solution under mechanical stirring followed by ultrasonication. As shown in Table 1, the size of the blank micelles was $252 \mathrm{~nm}$, and the size of the PTX-micelles ranged from 326 to $380 \mathrm{~nm}$. The hydrodynamic diameter increased with the increase in drug loading, suggesting that when more drug was entrapped in the micellar hydrophobic core, the micellar inner core volume was increased. The TEM image showed the size and morphology of the PTX-micelles (Figure 4), and the physical appearance of the PTX-micelles are shown in Figure 5. Clearly, the nanomicelles were spherical in shape with a homogeneous size distribution. The micellar solution was clear and colorless with

Table I Particle size, zeta potential, and encapsulation efficiency of PTX-loaded nanomicelles

\begin{tabular}{lllllrr}
\hline Micelles & $\begin{array}{l}\text { PTX:CS-VES } \\
\text { (charge ratio) }\end{array}$ & $\begin{array}{l}\text { Particle size } \\
(\mathbf{n m})\end{array}$ & Polydispersion & \multicolumn{1}{l}{$\begin{array}{l}\text { Zeta potential } \\
(\mathbf{m V})\end{array}$} & EE $^{\mathrm{b}}(\%)$ & $\mathbf{D L}^{\mathrm{c}}(\%)$ \\
\hline Blank micelles & - & $252.3 \pm 6.0$ & $0.459 \pm 0.009$ & $24.9 \pm 1.2$ & - & - \\
PTX-micelles & I:10 & $326.3 \pm 3.5$ & $0.475 \pm 0.013$ & $22.8 \pm 3.3$ & $81.82 \pm 0.95$ & $7.52 \pm 0.08$ \\
PTX-micelles & I:5 & $365.6 \pm 1.3$ & $0.390 \pm 0.011$ & $19.1 \pm 2.5$ & $82.03 \pm 0.77$ & $14.09 \pm 0.11$ \\
PTX-micelles & I:3 & $380.8 \pm 0.9$ & $0.357 \pm 0.030$ & $19.5 \pm 1.7$ & $81.12 \pm 0.56$ & $21.37 \pm 0.17$ \\
\hline
\end{tabular}

Notes: a Measurement was performed in deionized water $(\mathrm{pH} 7)$; ${ }^{b}$ drug encapsulation efficiency = (amount of drug loaded in the micelles/amount of drug added during fabrication) $\times 100$; cdrug loading ratio $=$ (amount of drug loaded in the micelles/the total amount of drug in the micelles and CS-VES conjugate used in the process) $\times 100$. Mean \pm standard deviation, $\mathrm{n}=3$.

Abbreviations: CS-VES, chitosan/vitamin E succinate; DL, drug loading ratio; EE, encapsulation efficiency; PTX, paclitaxel. 


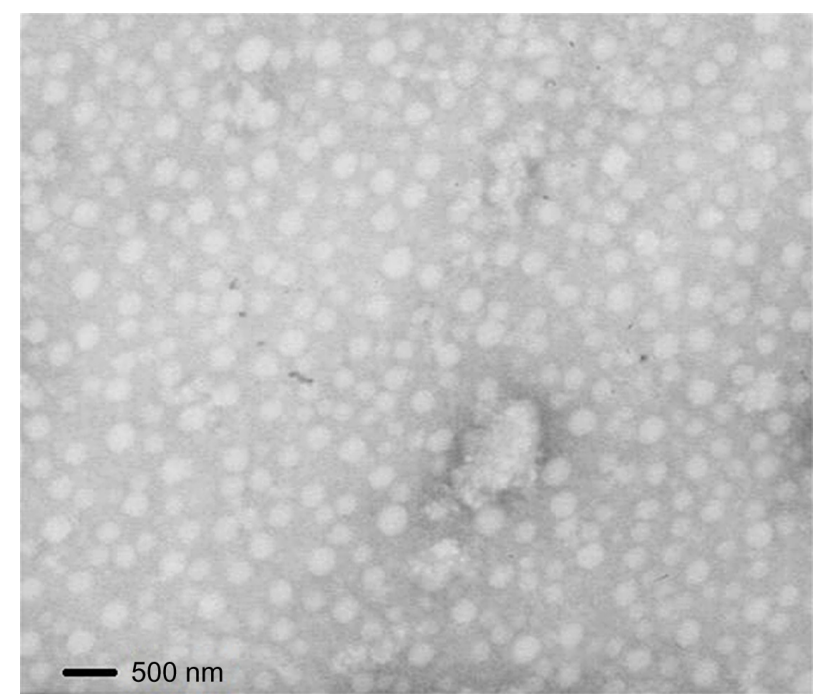

Figure 4 Transmission electron microscope image of paclitaxel-loaded micelles.

a light blue opalescence. The encapsulation efficiency of the PTX-micelles was over $80 \%$, showing that there was a good bioaffinity between PTX and the CS-VES nanocarrier.

The highest drug-loading content was about $20 \%$, indicating that PTX can be effectively solubilized by the CS-VES nanomicelles. The zeta potential not only plays an important role in the physical stability of the nanosystem, but also affects its interaction with the cell membrane. ${ }^{34}$ The zeta potentials of the blank-micelles and PTX-micelles were all positive and almost identical (Table 1). In this way, PTX

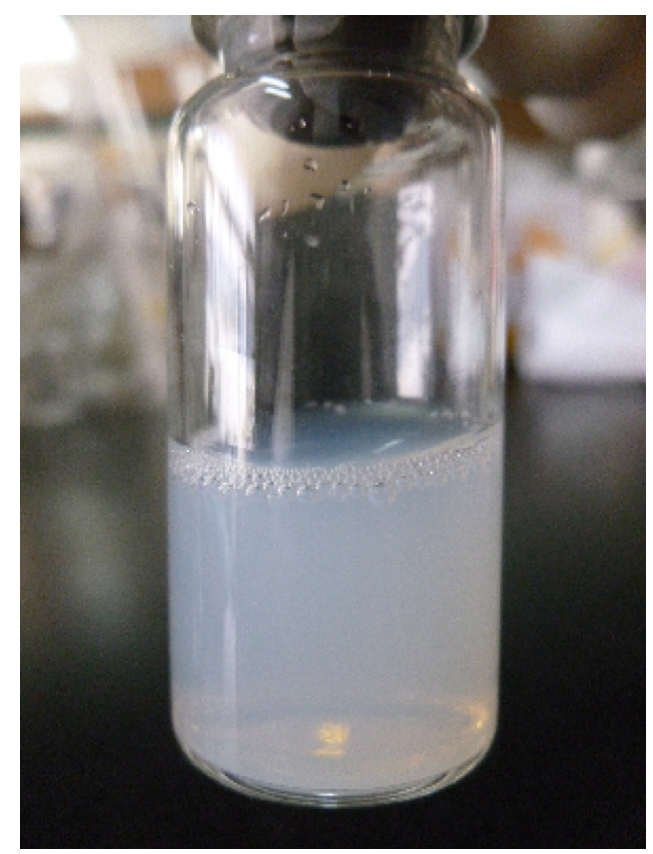

Figure 5 Physical appearance of paclitaxel-loaded nanoparticles. loading did not affect the surface charge of the micelles, proving that the positively charged nanomicelle system interacted well and there was strong adhesion to the negatively charged cell membrane.

\section{Physical status of PTX in the CS-VES nanomicelles}

$\mathrm{X}$-ray powder diffraction was used to characterize the physical existing status of PTX in the nanomicelles. As shown in Figure 6, diffraction peaks of PTX powder appeared from $5^{\circ}-25^{\circ}$, and these were also observed in the pattern of the physical mixture of PTX and blank micelles, but not in the pattern of PTX-loaded micelles.

DSC analyses of blank micelles, PTX-micelles, PTX, chitosan, and the physical mixture of PTX and blank micelles, were also conducted to further identify the physical status of PTX in the nanomicelles. The melting peak of pure PTX powder was about $213^{\circ} \mathrm{C}$, which also appeared in the curve of the physical mixture (Figure 7). However, no melting peak of PTX was observed in the diagram of the PTX-loaded nanomicelles.

The above results indicate that PTX was encapsulated into the nanomicelles in an amorphous form, and no crystal drug nanoparticles were present in the nanomicelles.

\section{In vitro release study}

Three drug loadings of PTX-micelles, 7.52\%, 14.09\%, and $21.37 \%$, and Taxol $(6 \mathrm{mg} / \mathrm{mL})$ were prepared to investigate the release profiles of CS-VES micelles in vitro. PBS ( $\mathrm{pH} 7.4$ ) containing $2 \% \mathrm{w} / \mathrm{v}$ Cremophor EL, was used as a release medium to maintain sink condition. The release results are presented in Figure 8. The Taxol formulation exhibited a fast drug release behavior in the first 10 hours, and the cumulative percentage release percent reached about

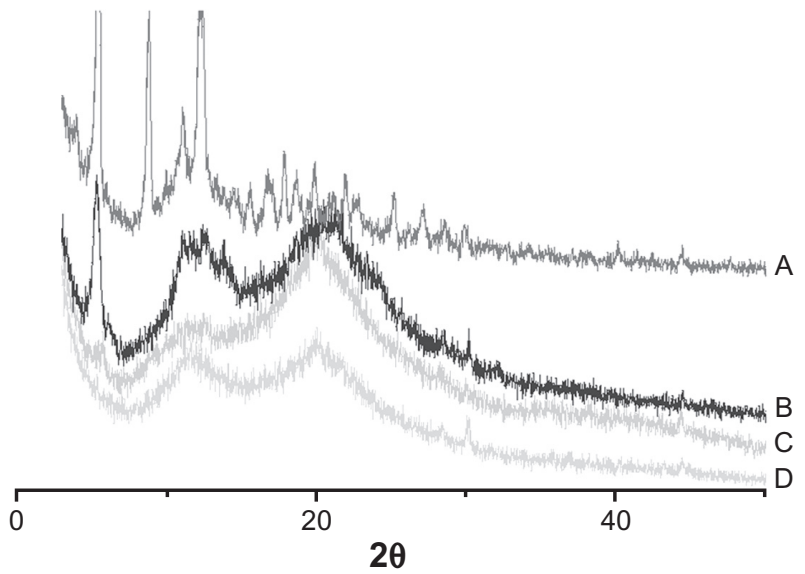

Figure 6 X-ray diffraction of: A, paclitaxel; B, physical mixture of blank micelles and paclitaxel (5:I [w/w]); C, paclitaxel-loaded micelles (drug loading $=14 \%$ ); and $\mathrm{D}$, blank micelles. 


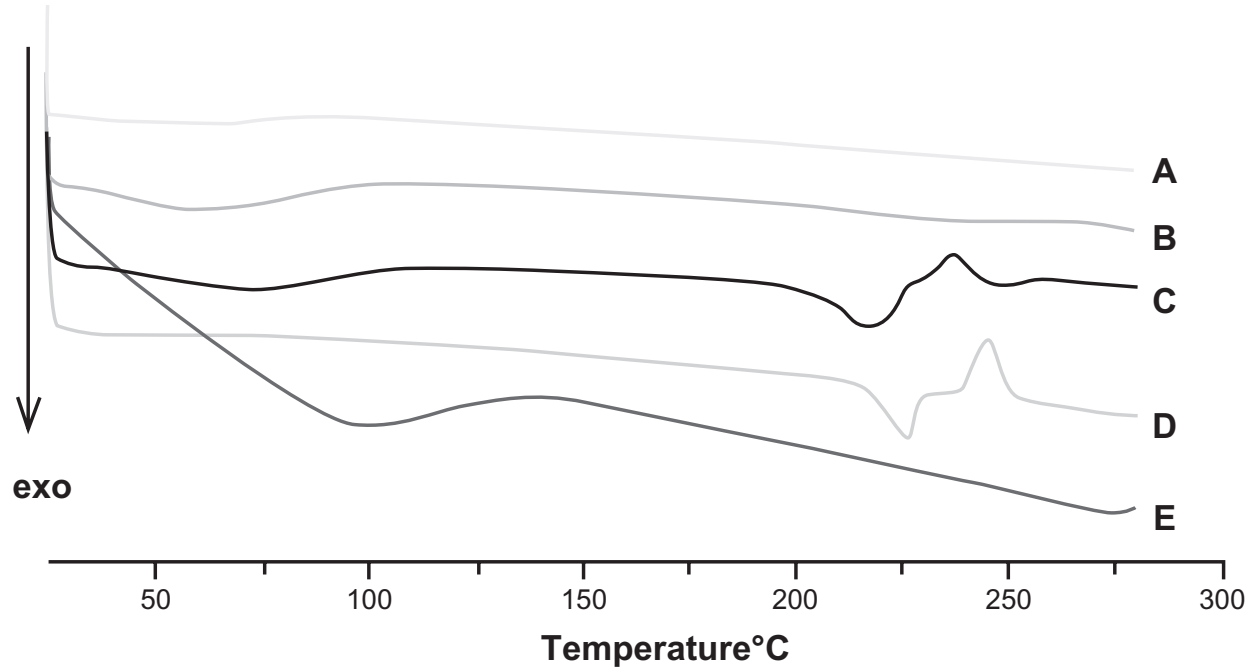

Figure 7 Differential scanning calorimetry thermograms of: A, blank micelles; B, paclitaxel-loaded micelles (drug loading = I4\%); C, physical mixture of blank micellar system and paclitaxel (5:I [w/w]); D, paclitaxel; and E, chitosan.

$80 \%$ in 12 hours. In contrast to Taxol, PTX-micelles showed a near zero-order sustained-release profile, and no apparent burst release was observed. Three different drug loadings of PTX-micelles all showed similar release profiles. The cumulative release percentage of PTX-micelles was about $22.31 \%$ during the initial 48 hours, and 34.61\% PTX was released from the PTX-micelles for up to 96 hours. The cumulative percentage release by 168 hours reached $51.06 \%, 50.88 \%$, and $44.35 \%$, respectively, for the three PTX-micelles. As seen from the structure and composition of the nanomicelles, the release of PTX from polymeric micelles was mainly due to diffusion during the early release stage; by contrast, the erosion rate of the biodegradable polymeric micelles may control the release behavior of PTX during the later release stage.

\section{In vitro cellular uptake}

The cellular internalization behavior of CS-VES nanomicelles containing coumarin- 6 on MCF-7 cells was examined by confocal laser scanning microscopy. In Figure 9, the fluorescence images of the coumarin- 6 solution and coumarin- 6 loaded micelles, following incubation in MCF-7 cells for 30 minutes, are shown in row 1 and row 2 . The images in row 3 and row 4 show similar processes, with the incubation time being

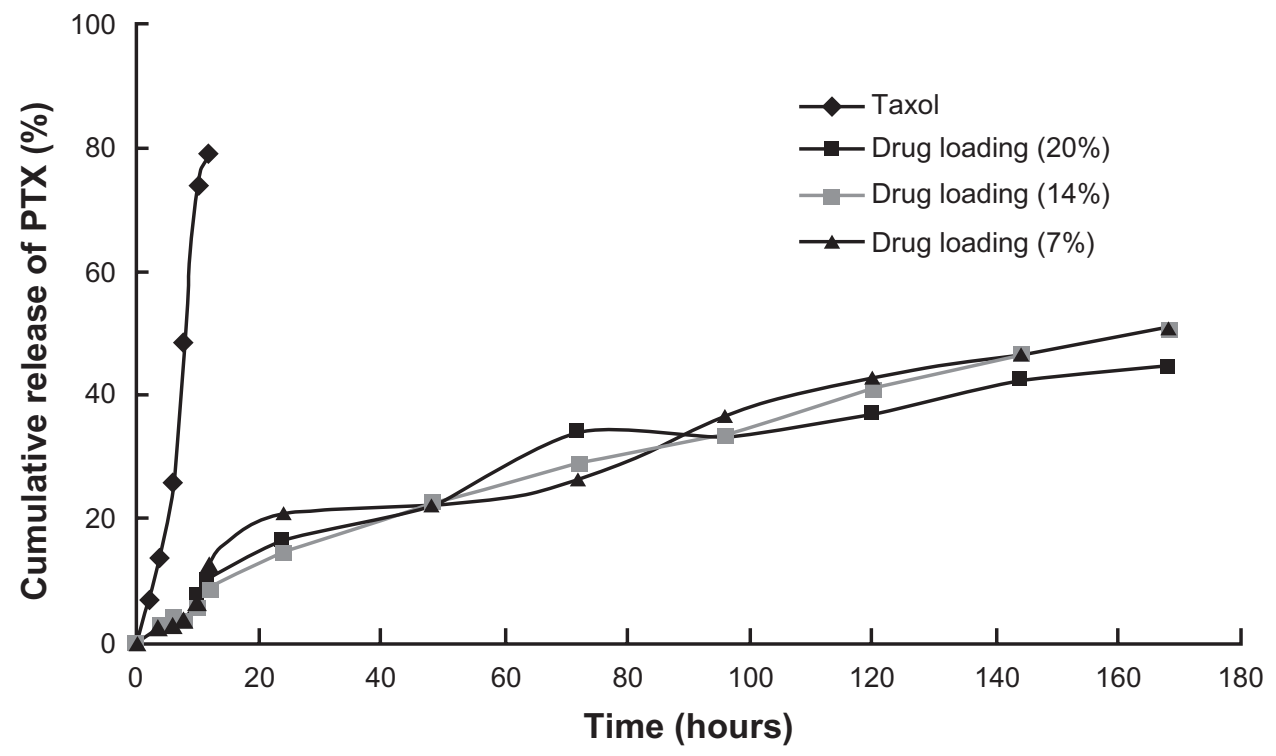

Figure 8 In vitro release profiles of paclitaxel (PTX) from chitosan/vitamin E succinate nanomicelles in pH 7.4 phosphate-buffered saline (containing $2 \%$ Cremophor $\left.E L^{\circledR}, w / v\right)$. 

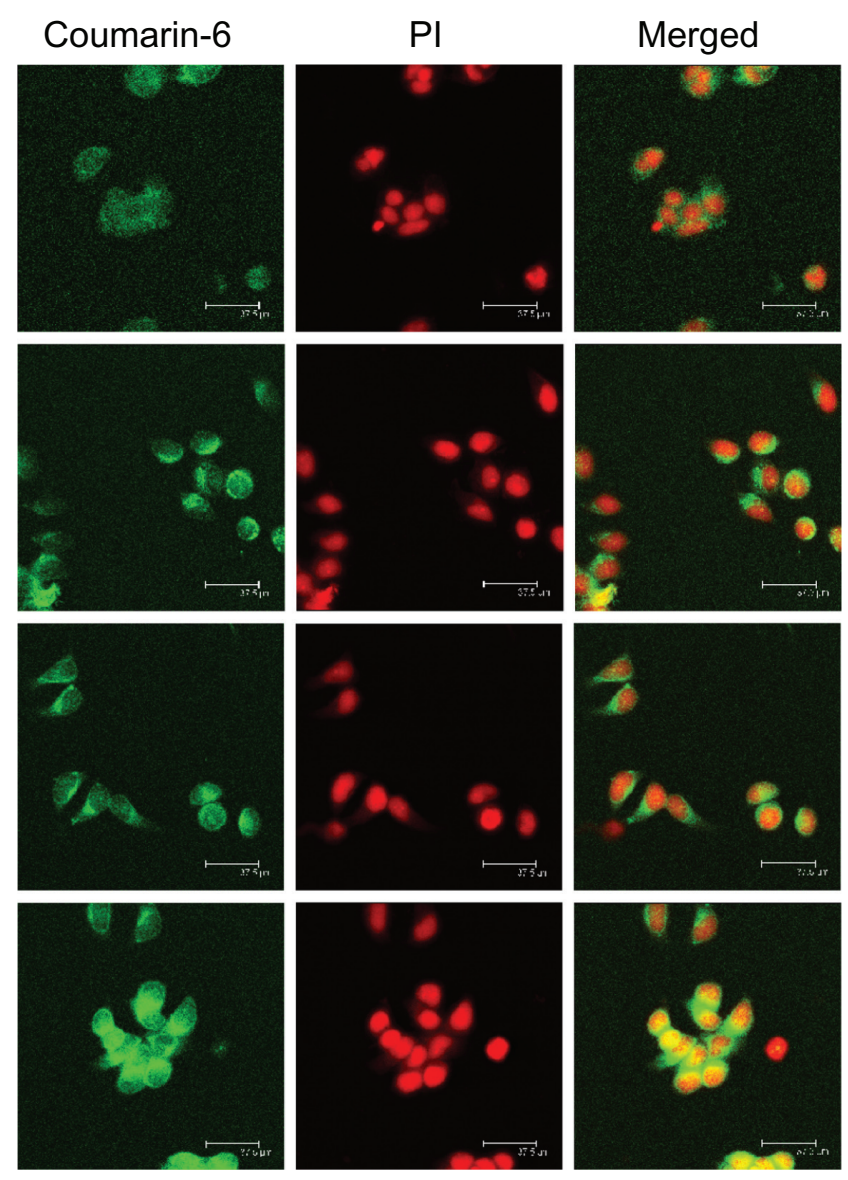

Figure 9 Confocal laser scanning microscopic images (in each column: left, fluorescein isothiocyanate channel; middle, rhodamine B isothiocyanate channel; right, merged images) of MCF-7 cells after 30 minutes' incubation with coumarin- 6 solution (row 1), coumarin-6-loaded micelles (row 2). Rows 3 and 4 show formulations similar to those in rows $I$ and 2, but incubation time was 2 hours.

Abbreviation: $\mathrm{PI}$, propidium iodide.

2 hours. The left column shows that the images obtained from the fluorescein isothiocyanate (FITC) channel corresponded to the green fluorescence of coumarin-6. The middle column shows the images from the rhodamine B isothiocyanate (RITC) channel which displayed the red fluorescence of nuclei stained with propidium iodide. The right column shows the merged images of the FITC and RITC channels. As seen from rows 1 and 2, the fluorescence intensity of the coumarin- 6 loaded micelles was significantly stronger than that of coumarin-6 solution, indicating that CS-VES nanomicelles were more efficiently taken up into the cancer cells. This might be due to the positive surface charge and appropriate particle size of the nanomicelles. When the incubation period reached 2 hours, a similar trend was observed in rows 3 and 4 , and the fluorescence intensity of coumarin- 6 loaded micelles was greater than that of coumarin- 6 solution. These results show that the cellular uptake of free courmarin-6, and courmarin-6-loaded CS-VES nanomicelles were time-dependent and the nanomicelles could be effectively endocytosed by MCF-7 cells. Similar findings have been reported previously. ${ }^{35}$ In addition, the fluorescence of CS-VES nanomicelles was much stronger in the cytoplasm than that at 0.5 hours, and the fluorescence became uniformly dispersed in the nuclei after incubation for 2 hours.

\section{In vitro cytotoxicity}

To evaluate the cytotoxicity of PTX formulated in CS-VES nanomicelles and Taxol, MTT assay was carried out to compare the cell viability after a 24-, 48-, and 72-hour incubation with MCF-7 cells at $37^{\circ} \mathrm{C}$, and the results are shown in Figure 10A. Generally, the cytotoxicity of the drug formulated in the Taxol and CS-VES nanomicelles increased along with the increase in the drug concentration and incubation time. It would be expected that a higher drug concentration and longer incubation time would allow more drug to enter into cells. After the 24-hour incubation, the cell viability of the Taxol formulation of 1,10 , and $100 \mathrm{ng} / \mathrm{mL}$ and a drug concentration of 1,10 , and $100 \mu \mathrm{g} / \mathrm{mL}$ was found to be $91.92 \%$, $83.79 \%$, and $71.72 \%$, and $60.07 \%, 47.74 \%$, and $13.22 \%$, respectively. The cell viability after the 48 -hour incubation for the Taxol formulation was $89.21 \%, 61.19 \%, 58.86 \%, 54.42 \%$, $45.15 \%$, and $2.82 \%$, and this decreased to $63.24 \%, 37.33 \%$, and $33.36 \%$, and $30.53 \%, 22.74 \%$, and $2.18 \%$, respectively, after 72 hours. Generally, the PTX-micelles exhibited a comparable but delayed cytotoxic effect compared with Taxol. The MCF-7 cell viability after a 24 -hour incubation at drug concentrations of $1,10,100 \mathrm{ng} / \mathrm{mL}$ and $1,10,100 \mu \mathrm{g} / \mathrm{mL}$ was about $88.46 \%, 80.64 \%, 75.18 \%, 69.78 \%, 63.85 \%$, and $47.43 \%$, and this reached $99.83 \%, 79.83 \%, 68.84 \%, 65.42 \%$, $52.79 \%$, and $23.58 \%$ after 48 hours. After 72 hours treatment, the cell viability was further decreased to $74.72 \%, 53.54 \%$, $43.24 \%, 37.15 \%, 26.41 \%$, and $3.16 \%$, respectively. The delayed cytotoxicity of the polymeric micelle systems was probably due to their sustained-release characteristics, and PTX required more time to be released into the cytoplasm, as suggested in Figure 11. The cytotoxicity of CS-VES copolymer was further compared with Cremophor EL. The results were shown in Figure 10B. Blank micelles showed obvious cytotoxicity, but a much stronger cytotoxcity was observed when the cells were incubated in the presence of Cremophor EL.

More importantly, one novel finding was that the blank CSVES nanomicelles were significantly cytotoxic to MCF-7 cells and could act as an anticancer efficacy enhancer for cytotoxic anticancer drugs. The cytotoxic effect of CS-VES copolymer was probably due to the apoptosis of VES, as reported in 

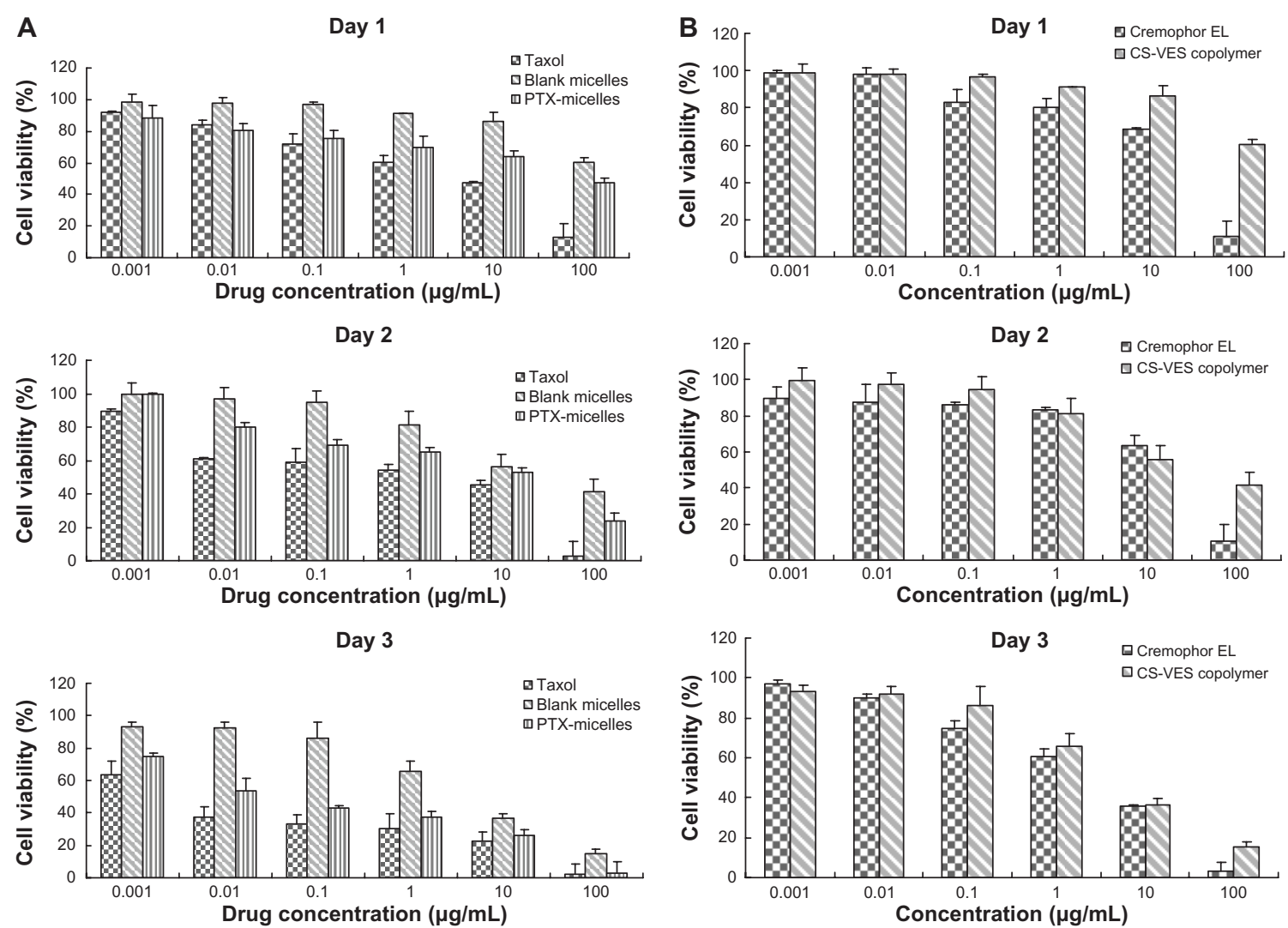

Figure 10 (A) Cytotoxicity of CS-VES copolymer compared with Cremophor EL ${ }^{\circledR}$. (B) Diagrams of cell viability cultured with PTX-loaded CS-VES micelles (PTX micelles) in comparison with Taxol ${ }^{\circledast}$ at the same dose and blank micelles at the same amount of copolymer.

Note: Data shown mean \pm standard error $(n=3)$.

Abbreviations: CS-VES, chitosan/vitamin E succinate; PTX, paclitaxel.

previous studies. ${ }^{27-30}$ The $\mathrm{IC}_{50}$ value was calculated using the cytotoxicity in MCF-7 cells after a 24, 48, and 72-hour incubation with Taxol and PTX-micelles (Table 2). The $\mathrm{IC}_{50}$ value after 24, 48, and 72 hours treatment were 2.104, 0.687,

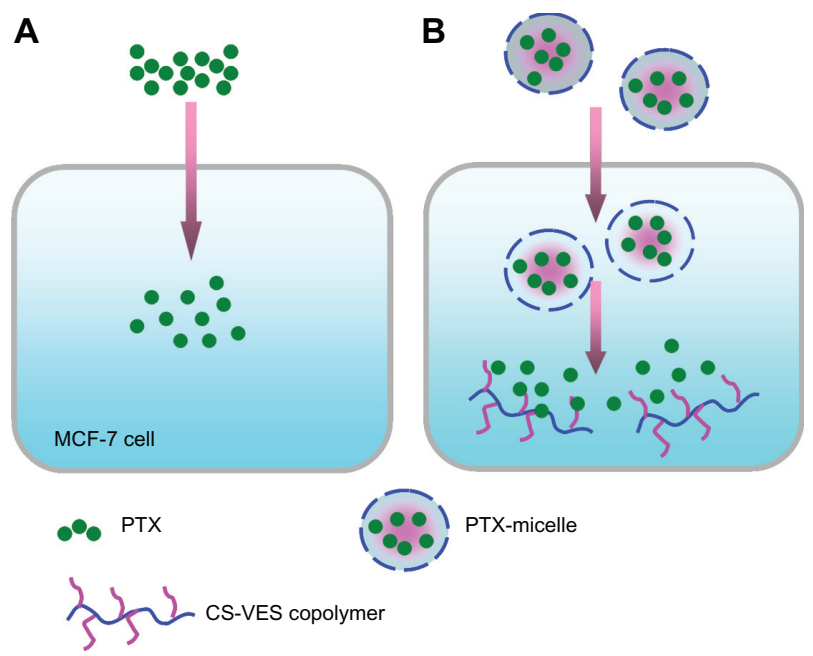

Figure II Schematic to explain the different cytotoxic effects of PTX solution and nanomicelles on an MCF-7 cell. (A) The rapid inhibition effect of PTX solution by diffusion. (B) The delayed cytotoxicity of PTX-nanomicelles by endocytosis and sustained-release profile.

Abbreviations: CS-VES, chitosan/vitamin E succinate; PTX, paclitaxel. and $0.0662 \mu \mathrm{g} / \mathrm{mL}$ for the Taxol formulation, $110.811,4.387$, and $0.152 \mu \mathrm{g} / \mathrm{mL}$ for PTX-micelles, and $378.774,17.568$, and $4.710 \mu \mathrm{g} / \mathrm{mL}$ for the blank micelles, respectively.

\section{Hemolysis test}

Since the supramolecular micellar aggregates are usually taken up by the intravenous route, a hemocompatibility test is needed to clarify the hemolysis of the novel CS-VES copolymer. The erythrocyte pellets in the samples with CS-VES copolymer were easily dispersed after stirring, and no aggregates were observed. There was no obvious difference between of the CS-VES copolymer compared with the negative control,

Table $2 \mathrm{IC}_{50}$ values in MCF-7 cells after 24-, 48-, and 72-hour incubation with PTX formulated in Taxol ${ }^{\circledR}$ (Bristol-Myers Squibb, New York, NY) and CS-VES micelles

\begin{tabular}{llll}
\hline Incubation & \multicolumn{2}{l}{$\mathrm{IC}_{50}(\mu \mathrm{g} / \mathrm{mL})$} \\
\cline { 2 - 4 } time (hours) & Taxol & Blank micelles & PTX-micelles \\
\hline 24 & 2.104 & 378.774 & $110.8 \mathrm{II}$ \\
48 & 0.687 & 17.568 & 4.387 \\
72 & 0.0662 & 4.710 & 0.152 \\
\hline
\end{tabular}

Abbreviations: CS-VES, chitosan/vitamin $\mathrm{E}$ succinate; $\mathrm{IC}_{5}$, half-maximal inhibitory concentration; PTX, paclitaxel. 

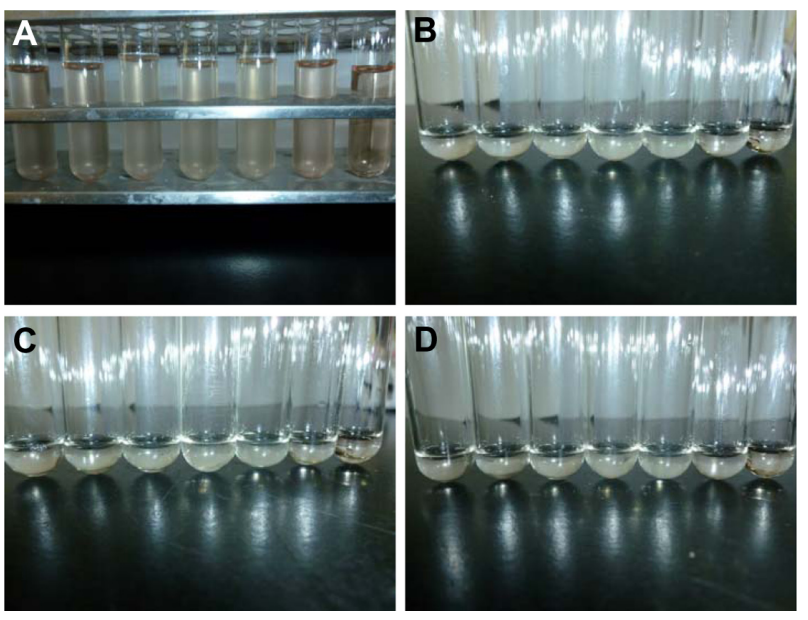

Figure 12 The results of hemolysis test of the novel chitosan/vitamin E succinate copolymer at different time intervals. The five tubes from the left were copolymer samples, the sixth was negative control and the last was positive control. At: (A) 0 hours, (B) I hour, (C) 2 hours, and (D) 3 hours.

as shown in Figure 12. Also, complete hemolysis was observed in the samples of positive control, and the solution was clearly faintly red. These results show that the CS-VES copolymer did not produce any hemolysis and erythrocyte agglutination at the highest concentration of $2 \mathrm{mg} / \mathrm{mL}$ at $37^{\circ} \mathrm{C}$, and so it is a safe nanocarrier for tumor-targeting drug delivery.

\section{Conclusion}

In this study, a novel self-assembled chitosan conjugate was synthesized with VES as the hydrophobic core for a water-insoluble anticancer drug reservoir and chitosan as the hydrophilic shell for bioadhesion. The new-type of CS-VES nanomicelles showed many fascinating features in terms of size, size distribution, zeta potential, high drug encapsulation efficiency, and sustained-release profile. The cellular uptake experiment demonstrated enhanced cellular uptake efficiency of PTX-micelles compared with the Taxol formulation. Owing to the introduction of VES into the nanocarrier and the enhanced endocytosis mechanism, PTX-loaded nanomicelles and even blank micelles exhibited significant cytotoxicity against MCF-7 cells. The hemolysis test showed that the CS-VES copolymer had a favorable safety profile. All of these results show that CSVES supramolecular micellar nanoaggregates have a promising future as nanocarriers for the delivery of anticancer drugs.

\section{Acknowledgments}

The authors are grateful for financial support from the National Natural Science Foundation of China (No 81173008). They would like to acknowledge the support of this work by the Key Project for Drug Innovation (2010ZX09401-304) and the National Basic Research Program of China (973 program, 2009CB930300).

\section{Disclosure}

The authors report no conflicts of interest in this work.

\section{References}

1. Arbuck SG, Christian MC, Fisherman JS, et al. Clinical development of Taxol. J Natl Cancer Inst Monogr. 1993;15:11-24.

2. Kingston DGI. The chemistry of taxol. Pharmacol Ther. 1991;52: $1-34$.

3. Rowinsky EK, Onetto N, Canetta RM, et al. Taxol: the first of the taxanes, an important new class of antitumor agents. Semin Oncol. 1992; 19:6:646-662.

4. Zhang JA, Anyarambhatla G, Ma L, et al. Development and characterization of a novel Cremophor ${ }^{\circledR}$ EL free liposome-based paclitaxel (LEP-ETU) formulation. Eur J Pharm Biopharm. 2005;59: $177-187$.

5. Lundberg BB, Risovic V, Ramaswamy M, et al. A lipophilic paclitaxel derivative incorporated in a lipid emulsion for parenteral administration. J Controlled Release. 2003;86:93-100.

6. Maranhão RC, Tavares ER, Padoveze AF, et al. Paclitaxel associated with cholesterol-rich nanoemulsions promotes atherosclerosis regression in the rabbit. Atherosclerosis. 2008;197:959-966.

7. Obara K, Ishihara M, Ozeki Y, et al. Controlled release of paclitaxel from photocrosslinked chitosan hydrogels and its subsequent effect on subcutaneous tumor growth in mice. J Controlled Release. 2005; 110:79-89.

8. Alani AWG, Bae Y, Rao DA, et al. Polymeric micelles for the $\mathrm{pH}$-dependent controlled, continuous low dose release of paclitaxel. Biomaterials. 2010;31:1765-1772.

9. Li H, Liu J, Ding S, et al. Synthesis of novel pH-sensitive chitosan graft copolymers and micellar solubilization of paclitaxel. Int J Biol Macromol. 2009;44:249-256.

10. Liu J, Li H, Jiang X, et al. Novel pH-sensitive chitosan-derived micelles loaded with paclitaxel. Carbohydr Polym. 2010;82:432-439.

11. Wei Z, Hao J, Yuan S, et al. Paclitaxel-loaded Pluronic P123/F127 mixed polymeric micelles: formulation, optimization and in vitro characterization. Int J Pharm. 2009;376:176-185.

12. Zhan $\mathrm{C}, \mathrm{Gu} \mathrm{B}, \mathrm{Xie} \mathrm{C}$, et al. Cyclic RGD conjugated poly(ethylene glycol)-co-poly(lactic acid) micelle enhances paclitaxel antiglioblastoma effect. J Controlled Release. 2010;143:136-142.

13. Branco MC, Schneider JP. Self-assembling materials for therapeutic delivery. Acta Biomater. 2009;5:817-831.

14. Jones MC, Leroux JC. Polymeric micelles - a new generation of colloidal drug carriers. Eur J Pharm Biopharm. 1999;48:101-111.

15. Kedar U, Phutane P, Shidhaye S, et al. Advances in polymeric micelles for drug delivery and tumor targeting. Nanomedicine. 2010;6: 714-729.

16. Rowan SJ. Polymer self-assembly: micelles make a living. Nat Mater. 2009;8:89-91.

17. Yokoyama M. Polymeric micelles as a new drug carrier system and their required considerations for clinical trials. Expert Opin Drug Deliv. 2010;7:145-158.

18. Kumar MN, Muzzarelli RA, Muzzarelli C, et al. Chitosan chemistry and pharmaceutical perspectives. Chem Rev. 2004;104:6017-6084.

19. Shahidi F, Abuzaytoun R. Chitin, chitosan, and co-products: chemistry, production, applications, and health effects. Adv Food Nutr Res. 2005;49:93-135.

20. Weecharangsan W, Opanasopit P, Ngawhirunpat T, et al. Evaluation of chitosan salts as non-viral gene vectors in CHO-K1 cells. Int J Pharm. 2008;348:161-168. 
21. Mathew ME, Mohan JC, Manzoor K, et al. Folate conjugated carboxymethyl chitosan-manganese doped zinc sulphide nanoparticles for targeted drug delivery and imaging of cancer cells. Carbohydr Polym. 2010;80:442-448.

22. Qu G, Yao Z, Zhang C, et al. PEG conjugated N-octyl-O-sulfate chitosan micelles for delivery of paclitaxel: in vitro characterization and in vivo evaluation. Eur J Pharm SCI. 2009;37:98-105.

23. Zhang C, Qineng P, Zhang H. Self-assembly and characterization of paclitaxel-loaded N-octyl-O-sulfate chitosan micellar system. Colloids Surf B Biointerfaces. 2004;39:69-75.

24. Zhang C, Qu G, Sun Y, et al. Pharmacokinetics, biodistribution, efficacy and safety of N-octyl-O-sulfate chitosan micelles loaded with paclitaxel. Biomaterials. 2008;29:233-241.

25. Hu FQ, Zhao MD, Yuan H, et al. A novel chitosan oligosaccharidestearic acid micelles for gene delivery: properties and in vitro transfection studies. Int J Pharm. 2006;315:158-166.

26. Hwang HY, Kim IS, Kwon IC, et al. Tumor targetability and antitumor effect of docetaxel-loaded hydrophobically modified glycol chitosan nanoparticles. J Controlled Release. 2008;128:23-31.

27. Neuzil J. Vitamin E succinate and cancer treatment: a vitamin E prototype for selective antitumour activity. Br J Cancer. 2003;89: $1822-1826$.

28. Neuzil J, Tomasetti M, Mellick AS, et al. Vitamin E analogues: a new class of inducers of apoptosis with selective anti-cancer effects. Curr Cancer Drug Targets. 2004;4:355-372.
29. Stapelberg M, Gellert N, Swettenham E, et al. Alpha-tocopheryl succinate inhibits malignant mesothelioma by disrupting the fibroblast growth factor autocrine loop: mechanism and the role of oxidative stress. J Biol Chem. 2005;280:25369-25376.

30. Yu W, Sanders BG, Kline K. RRR-alpha-tocopheryl succinate-induced apoptosis of human breast cancer cells involves Bax translocation to mitochondria. Cancer Res. 2003;63:2483-2491.

31. Stocks SJ, Jones AJ, Ramey CW, et al. A fluorometric assay of the degree of modification of protein primary amines with polyethylene glycol. Anal Biochem. 1986;154:232-234.

32. Cheon LS, Kim C, Chan KI, et al. Polymeric micelles of poly(2-ethyl2-oxazoline)-block-poly([var epsilon]-caprolactone) copolymer as a carrier for paclitaxel. J Controlled Release. 2003;89:437-446.

33. Yu JM, Li YJ, Qiu L, et al. Polymeric nanoparticles of cholesterolmodified glycol chitosan for doxorubicin delivery: preparation and in-vitro and in-vivo characterization. J Pharm Pharmacol. 2009;61: 713-719.

34. Chavanpatil MD, Khdair A, Panyam J. Nanoparticles for cellular drug delivery: mechanisms and factors influencing delivery. J Nanosci Nanotechnol. 2006;6:2651-2663.

35. He $\mathrm{C}, \mathrm{Hu} \mathrm{Y}$, Yin L, et al. Effects of particle size and surface charge on cellular uptake and biodistribution of polymeric nanoparticles. Biomaterials. 2010;31:3657-3666.
International Journal of Nanomedicine

\section{Publish your work in this journal}

The International Journal of Nanomedicine is an international, peerreviewed journal focusing on the application of nanotechnology in diagnostics, therapeutics, and drug delivery systems throughout the biomedical field. This journal is indexed on PubMed Central, MedLine, CAS, SciSearch ${ }^{\circledR}$, Current Contents ${ }^{\circledR} /$ Clinical Medicine,

\section{Dovepress}

Journal Citation Reports/Science Edition, EMBase, Scopus and the Elsevier Bibliographic databases. The manuscript management system is completely online and includes a very quick and fair peer-review system, which is all easy to use. Visit http://www.dovepress.com/ testimonials.php to read real quotes from published authors. 